Gaganan Awano and Mark Franklin Office for National Statistics

Jonathan Haskel and Zafeira Kastrinaki Imperial College, London

\title{
Measuring investment in intangible assets in the UK: results from a new survey
}

\section{Introduction}

\section{SUMMARY}

This article presents results of the Investment in Intangible Asset (IIA) Survey launched by ONS in October 2009. It is a new and unique survey of firms in the UK, drawn from the business register to represent the market sector of the economy. The survey is aimed at measuring investment of firms in six categories of intangible assets, these are: employer funded training, software, research and development (R\&D), reputation and branding, design, and business process improvement. The survey also set out to measure the life lengths of investments in each asset. The results show the overall level of intangible asset spending in the UK is considerable. The article explores the incidence, expenditure levels and life lengths of these assets.

\section{ro}

o complement recent macro work on intangible assets (Haskel et al, 2009),

this article reports on a new micro survey of intangible asset spending and life lengths. In October 2009, ONS surveyed $2,004^{1}$ UK private sector firms with ten or more employees, in the production and service sectors of the economy, drawn from the UK business register. Known as the Investment in Intangible Assets (IIA) Survey, it is a voluntary postal survey undertaken as part of the National Endowment for Science Technology and the Arts (NESTA) Innovation Index ${ }^{2}$ and conducted by the Office for National Statistics (ONS). Responses from 838 firms were obtained, a 42 per cent response rate which is considered high for a voluntary survey. Weights were calculated from the UK business register to generate population estimates to include firms with less than ten employees which were not surveyed. More details on the survey methodology can be found in the Appendix.

There are three main innovative features of the survey. First, as well as asking about R\&D spending, it also surveys a wider range of spending on intangibles: training, software, branding, design and business process. Second, since much spending on intangibles is in-house, it specifically asks firms about both purchased and in-house spending. Third, to estimate depreciation rates for intangibles, firms were asked about the length of time they expected to benefit from such spending.

This work is distinctive from other surveys, the bulk of which do not ask for all intangibles, but just one, such as R\&D or design. Thus it is possible to examine hypotheses such as those in Grilliches (1990), who conjectures that other innovation spending, not counted as R\&D, is likely important, especially for small firms. The main survey that does touch on intangibles is (various versions of) the Community Innovation Survey (CIS). However, that survey does not ask about all intangible categories (business processes for example), does not ask specifically about in-house (such as staff costs, associated costs including office facilities, overheads and so on) and purchased expenditure, a distinction that is found to be very important, and does not look at life lengths. Indeed, on the issue of life lengths, the only survey the authors are aware of is that of the Israeli Statistics Bureau (Peleg 2008a, 2008b). Thus it is believed that this survey provides some innovative micro information both to inform at the micro level and to check against the estimates used at the macro level ${ }^{3}$.

There are two main sets of findings, concerning intangible spending and life lengths.

Intangible spending: incidence and amount

The main findings here are as follows:

- the incidence of non-R\&D intangible spending is much more widespread than R\&D spending. Eight per cent of UK firms spend on R\&D, all of whom 
Table 1

\section{Survey response rate by firm size}

\begin{tabular}{lrr}
\hline Firm size & Usable response rate ${ }^{1}$ (per cent) & Positive response (per cent) \\
\hline $10-99$ & 47 & 50 \\
$100-499$ & 48 & 68 \\
$500-4999$ & 33 & 80 \\
$5000+$ & 21 & 76 \\
Total & 42 & 58 \\
\hline
\end{tabular}

Note:

Source: Authors' calculation

1 Usable response rate is the ratio of responses per size band divided by size band in the sample while positive response is the ratio of positive spending in one or more intangible assets divided by the total number of firms replied (per size band). Data are not weighted.

\section{Figure 1}

\section{Percentage of firms conducting intangible activity by asset category}

Percentages

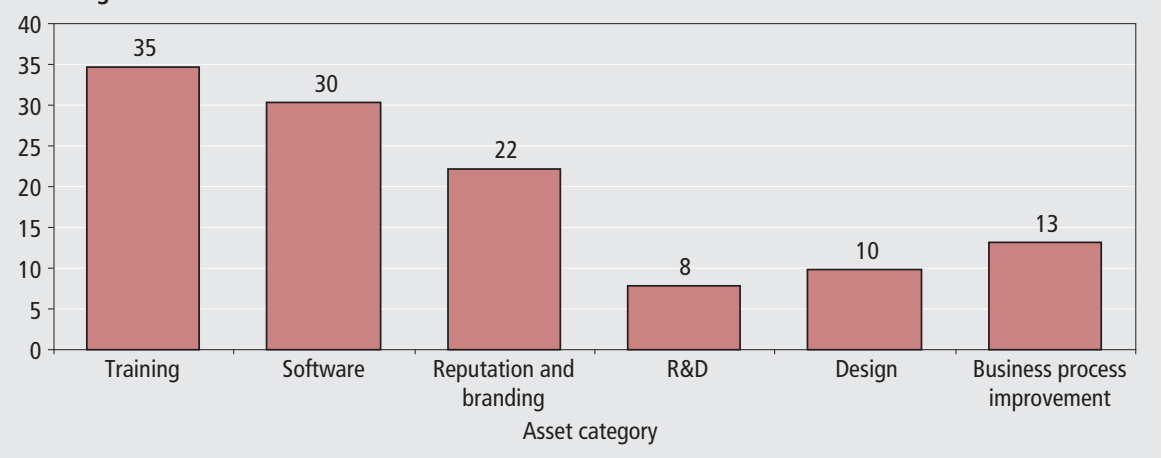

Source: Authors' calculation

Figure 2

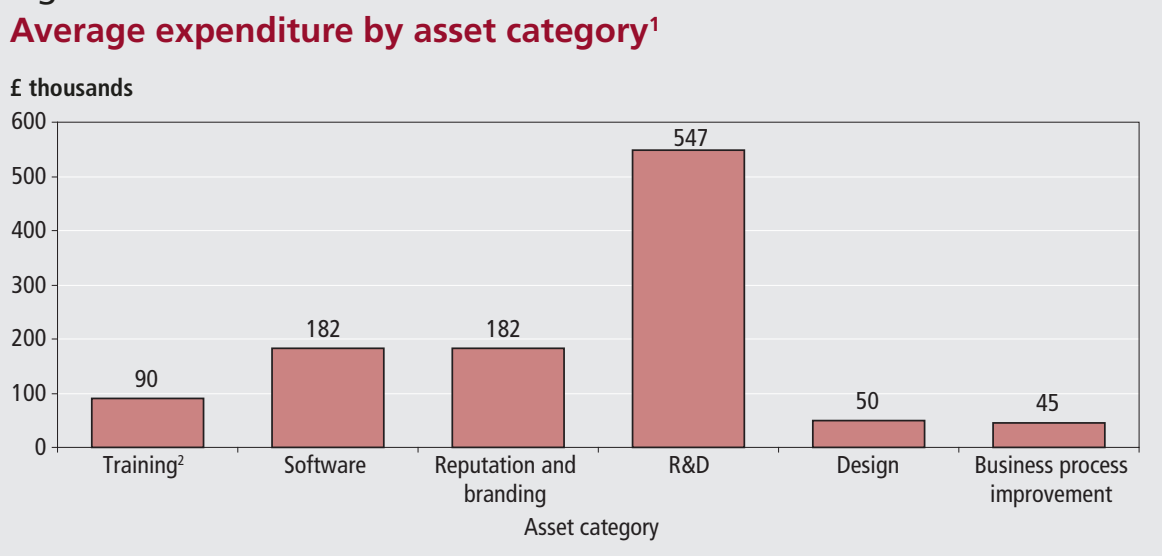

\section{Notes:}

1 Conditional on positive spending on that particular asset.

2 Training includes imputed costs of employee time during training.

also spend on non-R\&D intangible assets. But 50 per cent of UK firms spend on non-R\&D assets

- the incidence of both non-R\&D and $\mathrm{R} \& \mathrm{D}$ intangible spending is more common among large and older firms. But non-R\&D spending is much more common in services relative to manufacturing, especially in financial services. Thus much of the incidence of innovation spending in the service sector, a major part of the economy, is not captured in the R\&D statistics

- the overall level of intangible spending is considerable, around $£ 39 \mathrm{bn}$ in this survey, of which software is about $£ 11$ bn, branding $£ 10$ bn, R\&D £10bn, training $£ 7$ bn and design and business process improvement $£ 1$ bn each. In-house spending is, on average 55 per cent of this and purchased 45 per cent. Spending as a fraction of turnover (spending intensity) is particularly high in financial services and somewhat weakly higher in small firms

- taking into account differences in definition and timing, these micro numbers compare quite closely with the numbers used in a recent macro study for the UK Innovation Index (Haskel et al, 2009) for training, software, R\&D and branding. The micro numbers here are much lower than those in the macro data for design and business process engineering. This may have to do with sampling (for example according to the Design Council, 85 per cent of designers are in small firms outside the IIA sample) or the recession or inaccuracy of the assumptions upon which the macro numbers are based, all of which needs investigation in future work

\section{Life lengths}

The survey asked firms to report 'on average, how long the business expects to benefit from a typical investment in' each of the assets. The main findings are:

- average benefit lives for all intangibles were over 1 year, supporting the idea that intangible investment brings long-lived benefits. Indeed lowest of the 95 per cent confidence intervals for all assets were over 2 years, except for branding which was 1.9 years

- R\&D had the longest average benefit life of 4.6 years; the average of the others was 3.2 years

\section{Results}

\section{Discussion of response rates}

Table 1 summarises the breakdown of the sample response rate by employment size bands. Higher response rates were obtained from smaller firms than for large firms. The total response rate for the survey at the close of the response period in January 2010 was 42 per cent. When analysing respondents who answered positively to spending in any of the intangible asset categories, an inverse trend was observed, that is relatively more of the larger firms who responded to the survey report spending on intangible assets than smaller firms. Overall 58 per cent of the total respondents had positive spending on one or more category of intangible assets.

All subsequent data are weighted to reflect the characteristics of the population from which the sample was drawn and the pattern of responses received. Note that, although the survey sample excludes firms with fewer than 10 employees, the population estimates for expenditure scale up to the whole population, using employment weights.

Incidence of expenditure by asset Figure 1 shows the incidence of each category of intangible activity; that is, the weighted fraction of firms reporting 


\section{Figure 3}

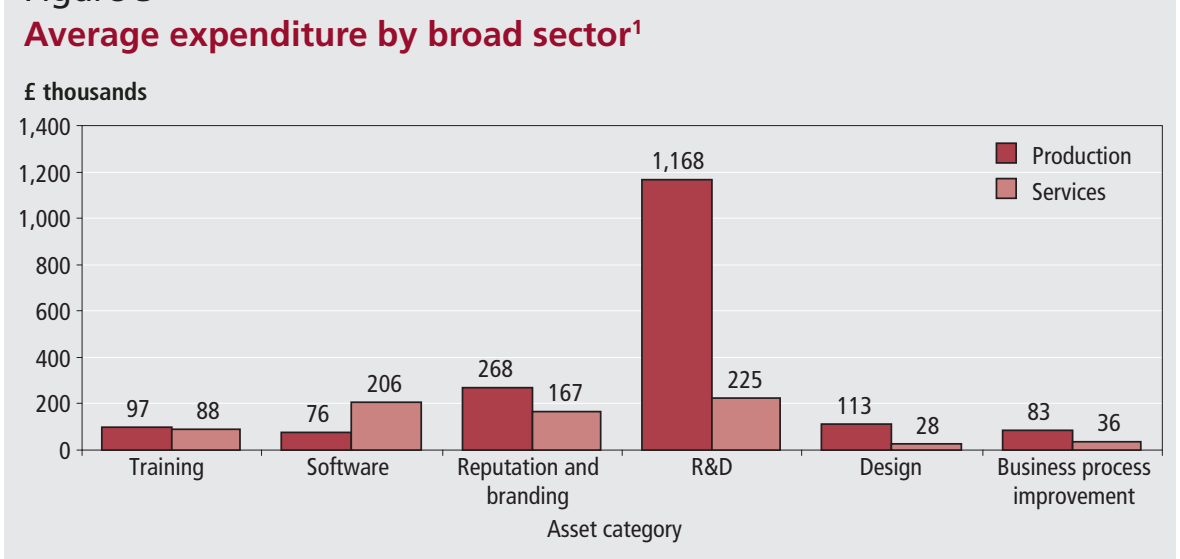

\section{Note:}

1 Conditional on positive spending on that particular asset.

\section{Figure 4 \\ Total expenditure by category ${ }^{1}$}

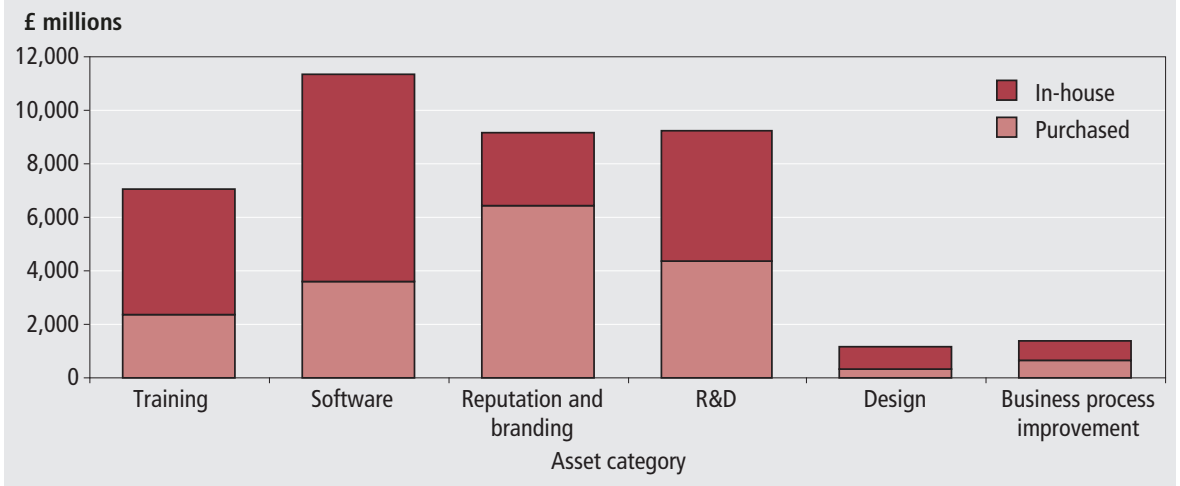

Note:

1 Weighted to give estimates of UK totals.

\section{Figure 5}

Weighted total expenditure by asset category and broad size class

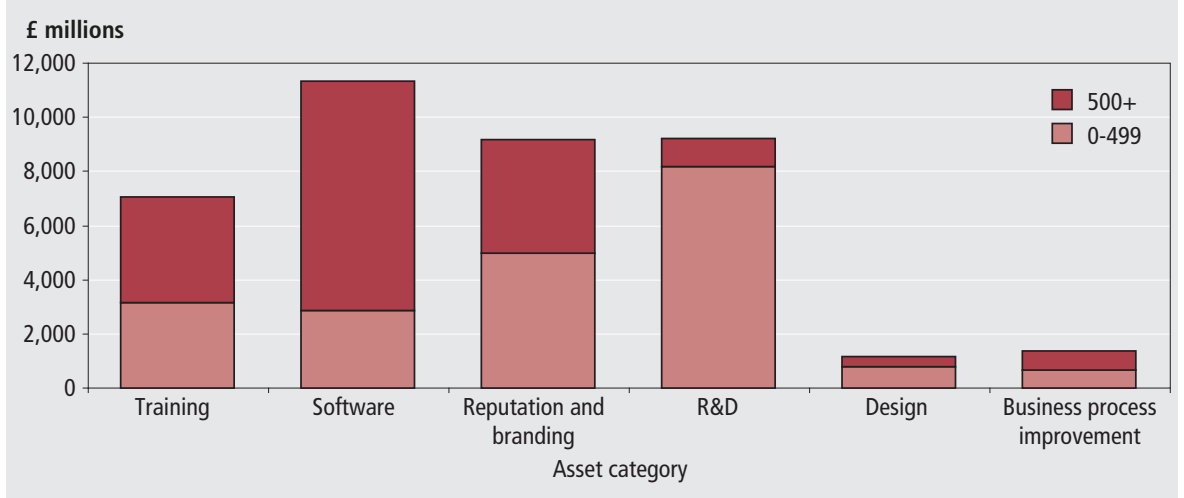

Source: Authors' calculation

positive intangible spending for each of the six assets. In other words, the percentage of firms saying 'yes' to total (internal plus external) intangible investment by asset category, weighted to be representative of the UK population of firms with 10 or more employees. Not surprisingly, employer funded training has the highest incidence, with just under 35 per cent of respondents reporting some training activity in the last year ${ }^{4} . R \& D$ had the lowest incidence at around 8 per cent.

This figure confirms that non-R\&D intangible spending is much more widespread than R\&D spending. In weighted terms, around 50 per cent of firms are active in one or more category of intangible asset including R\&D, and almost the same percentage are active in one or more category excluding $\mathrm{R} \& \mathrm{D}$. That is to say, only a tiny fraction of firms are found to be exclusively active in R\&D. Put another way, almost all firms who are active in $\mathrm{R} \& \mathrm{D}$ are also active in one or more other category of intangible asset but the converse is not true. The survey results suggest that 42 per cent of firms are not active in $R \& D$ but are active in one or more other category of intangible spending.

Average expenditure by asset for firms undertaking positive spending in that asset

This section looks at average spending on each asset conditional on reporting positive spending. There are large differences in the average expenditure on each asset category. Figure 2 shows that R\&D has by far the largest average level of expenditure followed by reputation and branding and then software, while average spending on training, design, and business process improvement are relatively smaller.

In Figure 3, the broad industry split reveals that except for software, firms in the production sector exhibit larger average spending on all other asset categories than firms in the services sector. Average expenditure naturally correlates with the size of the firm. However, the average size of firms in the production and service sectors is almost identical in terms of employment, so this finding would suggest that investment in intangibles - with the exception of software - is more intensive, relative to the size of the firm as measured by employment, in the production sector.

\section{Expenditure levels}

Figure 4 brings together the data on incidence and average expenditure to show weighted overall spending levels by asset category, broken down into purchased and in-house expenditure. Taking all expenditure together, the survey results suggest that software is the largest category, with total scaled expenditure estimated at a little over $£ 11$ bn. Total expenditure on $R \& D$ and on reputation and branding are both estimated at around $£ 9 \mathrm{bn}$, with training expenditure estimated at around $£ 7 b^{5}$. The remaining categories of design and business process improvement are both estimated at around $£ 1$ bn.

Thus the survey results confirm that while $\mathrm{R} \& \mathrm{D}$ is an important component of intangible investment and a source of innovation, it is not the only component. Moreover, the distribution of $\mathrm{R} \& \mathrm{D}$ expenditure differs markedly from the distribution of other categories of intangible investment. 


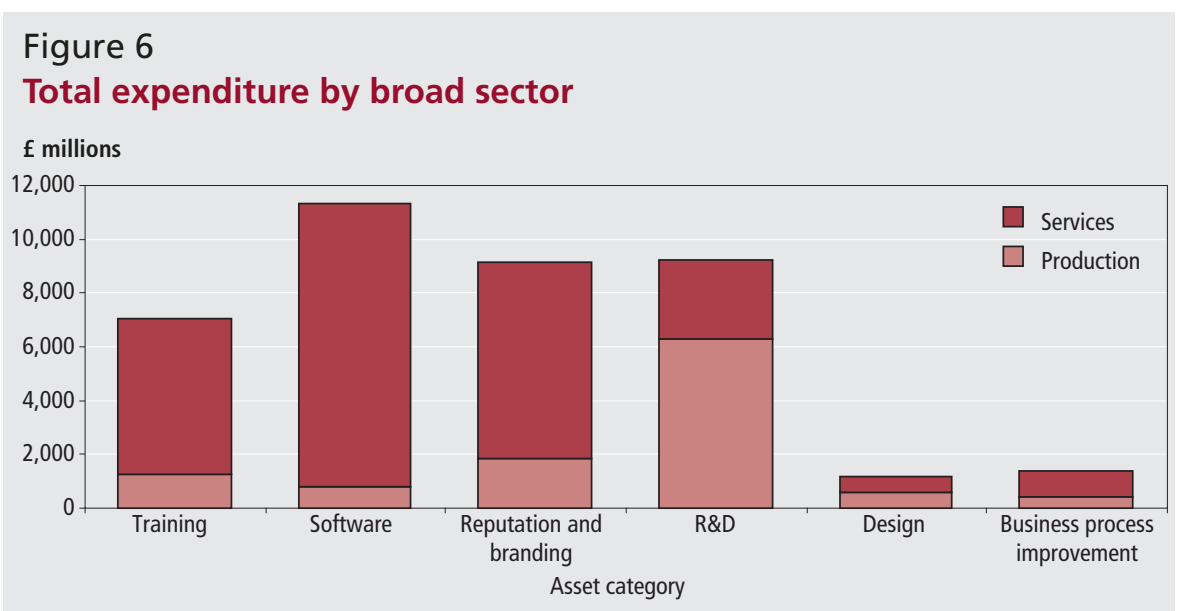

Source: Authors' calculation

Figure 7

Total expenditure by category- 95 percent confidence intervals

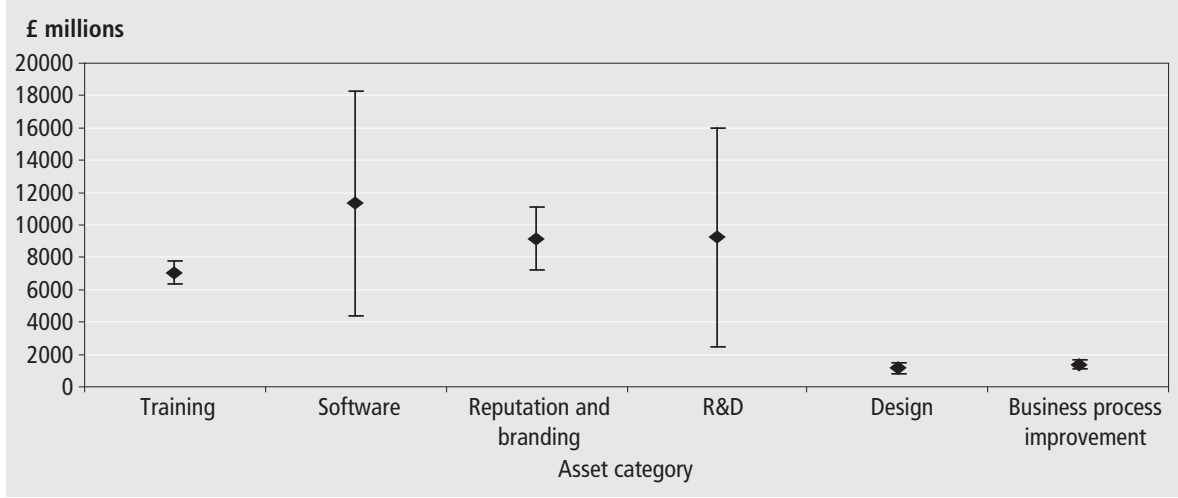

Source: Authors' calculation

Figure 8

\section{Average benefit lives with confidence intervals by asset ${ }^{1}$}

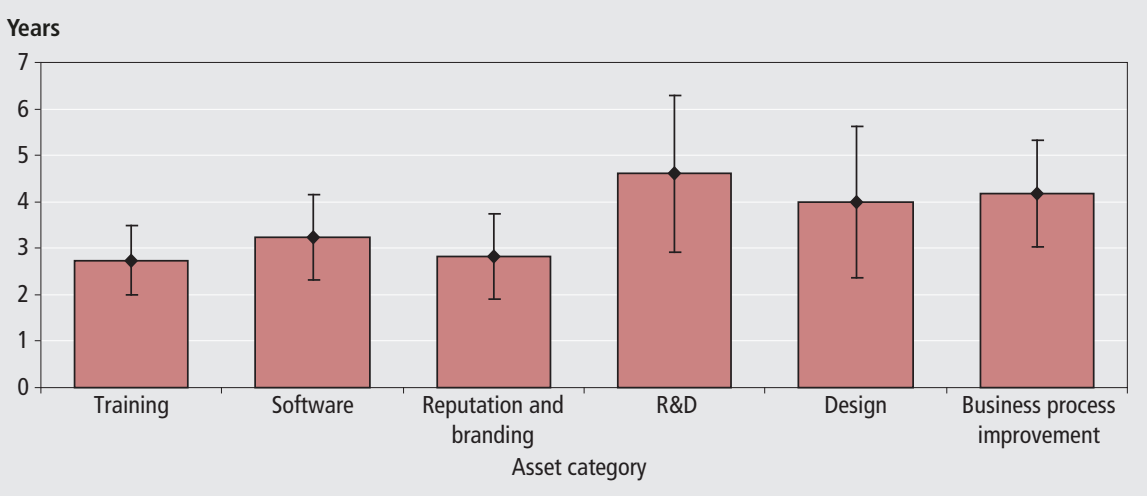

Note:

Source: Authors' calculation

1 Weighed by a-weights (see Appendix).

Figure 4 also shows that in-house investment is an important component in all categories, and especially so for design, software and training. The split between in-house investment and purchased investment is around 50:50 for R\&D and business process improvement. Only in the reputation and branding category is in-house investment significantly less than half of the total. Taking all six categories of intangibles together, the survey results give design show a bias towards smaller firms on this categorisation. Taking all intangibles together, the survey results suggest that intangible investment per employee is a little greater in larger firms than in smaller firms.

The expenditure split by broad sector is shown in Figure 6. The interesting feature of this analysis is not that expenditure is generally higher in the service sector which accounts for around 80 per cent of firms in the population, and a similar share of gross value added. But rather that expenditure on R\&D and design is higher in the production sector.

Given the particular characteristics of R\&D highlighted by this survey, it is not surprising that the survey results suggest that the breakdown between in-house and purchased spending differs across the broad sectors. The overall share of in-house investment is significantly higher among firms in services than those in the production sector, and there are some marked differences across individual asset categories, although some of these may be due to small sample sizes.

Figure 7 shows illustrative 95 percent confidence intervals ${ }^{6}$ for total expenditure on each category of intangible asset. It can be seen that confidence intervals around the expenditure estimates vary widely across the different categories. The range of the estimates is relatively narrow for design, training and business process improvement, somewhat wider for reputation and branding, and wider still for software and R\&D. Other things equal, the larger the sample size, the narrower the proportionate confidence intervals. Thus we would expect proportionately wider confidence intervals for expenditure sub-aggregates, such as in-house and purchased components of expenditure.

Life lengths of intangible assets As well as the magnitude of expenditure, the survey was designed to capture information on the life length of a typical investment in each category of intangible asset. Such information is useful both in forming a judgement as to whether investment in intangibles can be viewed as investment in the context of the national accounts (for which there is a de facto cut-off period of one year) and also in the practical implementation of growth accounting, which requires estimates to be made on depreciation rates of each class of asset.

The survey results for weighted average benefit lives of each asset category are shown in Figure 8. All are comfortably greater than one year, and range from 


\section{Figure 9}

\section{Average benefit lives by broad sector}

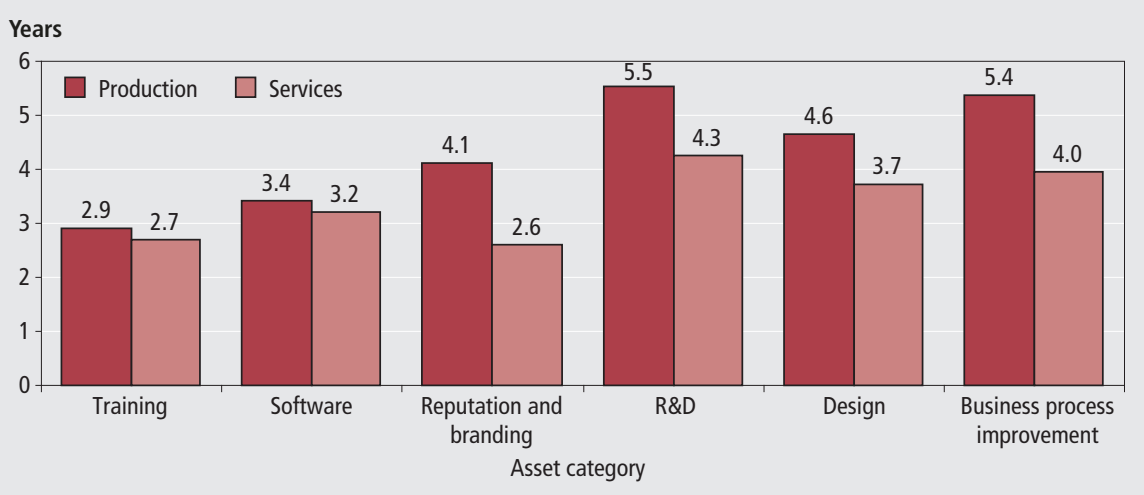

Source: Authors' calculation

\section{Figure 10}

\section{Average benefit lives by broad size class}

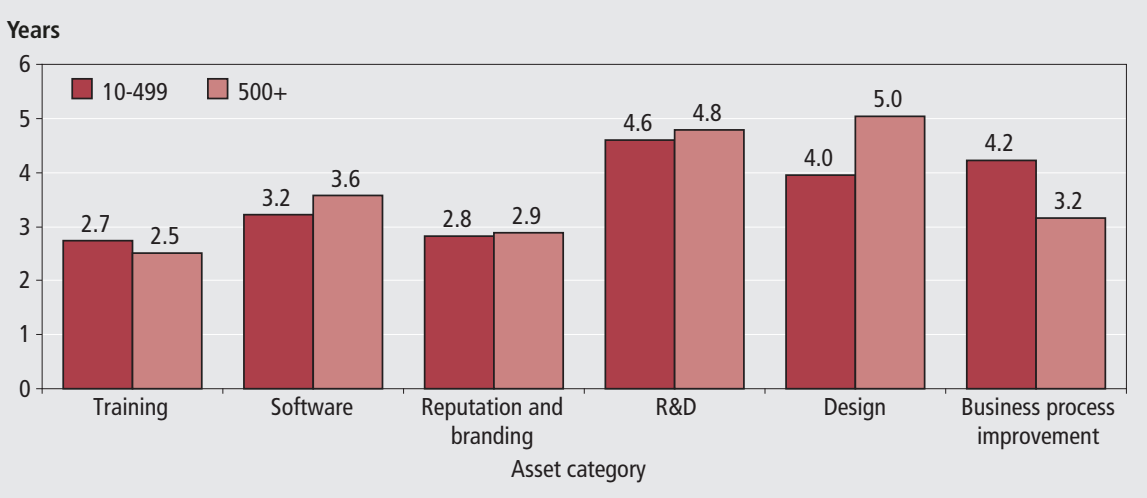

Source: Authors' calculation

2.75 years for training and reputation and branding, to around 4.5 years for R\&D. This quite strongly supports the case for capitalising intangible assets.

Confidence intervals around the benefit life estimates are also shown in Figure 8. The methodology here varies slightly from that used to estimate confidence intervals for expenditure in that it depends on the number of respondents providing estimates of benefit lives in each category ${ }^{7}$. This, alongside the distribution of the underlying data, is a factor in the fairly wide range for design, where the number of observations on benefit lives reflects the low incidence of this category.

The broad sector split (Figure 9) shows the production sector having longer life lengths in all asset categories compared to the services sector. Significant variations however are in $\mathrm{R} \& \mathrm{D}$, reputation and branding and business process improvement, where production sector benefit lives exceed those in the services sector by more than one year.

By contrast, analysing average benefit lives by broad size class shows no clear pattern (Figure 10). For four categories of intangibles - training, software, reputation and branding and R\&D - there is little difference in reported benefit lives between small and larger firms. Larger firms report longer benefit lives (by around a year) for design, whereas the reverse is true for business process improvement.

\section{Notes}

1. This sample size is small compared with other business surveys. Accordingly, care should be taken in drawing inferences from the survey results.

2. NESTA has been tasked in the Government White Paper Innovation Nation to create an index that measuresm innovation in the UK and informs innovation policy.

3. See Haskel et al, 2009

4. Our expectation that training would be more prevalent than some other categories was a factor in designing the survey questionnaire with the training questions first.

5. Training is off-the-job training. Note also that in this section the population refers to all firms, including those with fewer than 10 employees.

6. Estimated confidence intervals are based on the distribution of survey responses in each cell or set of cells in the sample frame (see Appendix for more details).

7. Population estimates of expenditure implicitly assume zero expenditure for respondents who do not engage in intangible investment. However, it would clearly be inappropriate to assume that benefit lives for such respondents were zero, so the population estimate and confidence intervals around that estimate depend only on positive responses.

\section{ACKNOWLEDGEMENT}

This work is an important component of NESTA's innovation index project and carried out by a team at ONS and Imperial Business School. We thank all who have supported and contributed to the project especially the survey respondents. All errors are the responsibility of the authors.

The full report (Investing in Innovation: Findings from the UK Investment in Intangible Asset Survey) can be found in the NESTA website at http://nesta.org.uk

\section{REFERENCES}

Camus D (editor) (2007) 'ONS Productivity Handbook: A Statistical Overview and Guide', Office for National Statistics. Available at: www.ons.gov.uk/about-statistics/userguidance/productivity-handbook/index.html

Grilliches Z (1990) 'Patent Statistics as Economic Indicators: A Survey', Journal of Economic Literature, Vol. 28, pp.1661-1707

Haskel J (2009) 'Innovation, knowledge spending and productivity growth in the UK', Interim report for NESTA Innovation Index project, NESTA, November 2009.

Peleg S (2008a) 'Service lives of R\&D', Central Bureau of Statistics, Israel

Peleg S (2008b) 'Examples of surveys on service lives of R\&D', OECD Task Force on R\&D and Other Intellectual Property Products.

Robson S and Kenchatt M (2010) 'First findings from the UK Innovation Survey 2009', Economic and Labour Market Review, Vol. 4 No. 3 March 2010.

Wallis, Gavin (2009), 'Capital Services Growth in the UK: 1950-2006', Oxford Bulletin of Economics and Statistics, Vol. 71, No. 6.

Whittard D, Franklin M, Stam P and Clayton T (2009) 'Testing an extended R\&D survey: Interviews with firms on innovation investment and depreciation', NESTA Innovation Index Working Paper, April 2009 


\section{APPENDIX}

\section{Methods Explained}

The Investment in Intangible Assets (IIA) Survey was a voluntary postal survey funded by the National Endowment for Science Technology and the Arts (NESTA) and conducted by the Office for National Statistics (ONS).

The Investment in Intangible Assets (IIA) Survey is part of a wider Innovation Index work by NESTA. This survey is a contribution of the ONSIImperial College stream of the Innovation Index work. Further details of NESTA's Innovation Index can be found at: http://nestainnovation.ning.com/

The Investment in Intangible Assets (IIA) Survey sampled 2,004 UK firms. It was a voluntary survey and was conducted by means of a postal questionnaire. The questionnaire and micro data can be found at the ONS Virtual Microdata Laboratory (VML). Details of the VML can be found at : www.ons.gov.uk/about/who-we-are/our-services/vml/index.html

\section{Coverage and sampling}

The survey covered firms with ten or more employees in sections B to N of the Standard Industry Classification (SIC) 2007

The sample was drawn from the ONS Inter-departmental Business Register (IDBR). Sampling was adjusted to reduce the sample weight on construction, utilities and Sections $G$ (Distribution), $\mathrm{H}$ (Transport) and I (Accommodation) of the service sector. This follows UK Innovation Survey findings of below average levels of innovation in these sectors. By contrast, the sample selection mildly over-sampled engineering-based manufacturing, Section J (Information and Communication) and Section K (Financial and insurance activities).

\section{Weighting}

The ' $a$ ' weights are computed as N(no. in population) / $\mathrm{n}$ (no. of respondents) for each cell of the sample frame. The ' $a$ ' weights should be used for all weighted aggregates except expenditure. For expenditure, aggregates should use the product of the ' $a$ ' and ' $g$ ' weights. The g-weights are based on the relationship between the characteristic of interest and supplementary information (called auxiliary data) and are also known as model weights.The ' $g$ ' weights use employment as the auxiliary variable, and use a clustering based on optimising the correlation between clustered employment and a synthetic variable which is the sum of all expenditure across categories.

\section{Confidence intervals}

The method of computing confidence intervals varies slightly according to the variable in question. Here we outline the method in the case of expenditure estimates.

Define: $\hat{Y}$ the population estimate of the expenditure variable $Y$ for which the confidence interval is to be computed.

$R_{j}=\operatorname{Sum}(a y)_{j} / \operatorname{Sum}(a x)_{j}$ - the ratio of a-weighted expenditure to a-weighted employment in each j-cell.

$$
\begin{array}{ll}
\text { Compute: } & \hat{S}_{a}^{2}=\sum\left(y-R_{j} * x\right)^{2} /\left(n_{a}-1\right) \\
& \operatorname{Var}\left(\hat{Y}_{a}\right)=N_{a}^{2} *\left(1-n_{a} / N_{a}\right) * \hat{S}_{a}^{2} / n_{a} \\
\text { Then: } \quad \operatorname{Var}(\hat{Y})=\sum \operatorname{Var}\left(\hat{Y}_{a}\right) \\
\text { And: } \quad \operatorname{SE}(\hat{Y})=\sqrt{\operatorname{Var}(\hat{Y})}
\end{array}
$$

$$
\text { for each a-cell }
$$$$
\text { for each a-cell }
$$

population variance estimate population standard error estimate

The 95 per cent confidence intervals are then $+/-1.96$ standard errors around the population estimate. 